\title{
Detection of BRAF mutation in thyroid papillary carcinomas by mutant allele-specific PCR amplification (MASA)
}

\author{
Maria Rosaria Sapio, Daniela Posca, Giancarlo Troncone ${ }^{1}$, Guido Pettinato ${ }^{1}$, Lucio Palombini ${ }^{1}$, Guido Rossi ${ }^{2,3}$, \\ Gianfranco Fenzi and Mario Vitale \\ Department of Endocrinologia ed Oncologia Molecolare e Clinica, Università Federico II, Via S. Pansini, 5 Napoli, 803131 Italy, ${ }^{1}$ Department of Scienze \\ Biomorfologiche e Funzionali, Università Federico II, Naples, Italy, ${ }^{2}$ Department of Biologia e Patologia Cellulare e Molecolare, Università Federico II, \\ Naples, Italy and ${ }^{3}$ Institute of Endocrinologia ed Oncologia Sperimentale 'G. Salvatore', Consiglio Nazionale delle Ricerche, Naples, Italy \\ (Correspondence should be addressed to M Vitale; Email: mavitale@unina.it.)
}

\begin{abstract}
Objective: The somatic point mutation in the BRAF gene, which results in a valine-to-glutamate substitution at residue $600\left(\mathrm{BRAF}^{\mathrm{V} 600 \mathrm{E}}\right)$, is an ideal hallmark of papillary thyroid carcinoma (PTC). However, its prevalence is varyingly reported in different studies, and its expression in the follicular variant PTC is controversial, reducing its potential usefulness as diagnostic marker.

Design and methods: We developed an assay based on mutant allele-specific PCR amplification (MASA) to detect BRAF mutation. We compared the sensitivity of MASA, single-strand conformation polymorphism (SSCP) and direct DNA sequencing of PCR products. Then, we used MASA 78 to analyze 78 archival thyroid tissues, including normal samples, follicular adenomas, follicular carcinomas and PTC.

Results: The MASA assay proved to be a more sensitive method than SSCP and DNA sequencing of PCR products. BRAF mutation was found by MASA in 19/43 (44.2\%) of PTC, including 14/31 $(45.2 \%)$ classic forms and 5/12 (41.7\%) follicular variants. No mutations of BRAF were detected in the normal thyroid tissues, nor in follicular adenomas or follicular carcinomas. No correlation was found between BRAF mutation and clinicopathologic features nor with recurrence during a postoperative follow-up period of 4-11 years. $\mathrm{BRAF}^{\mathrm{V} 600 \mathrm{E}}$ significantly correlated with absence of node metastasis.

Conclusions: $\mathrm{BRAF}^{\mathrm{V} 600 \mathrm{E}}$ is present in PTC, both in the classic form and in follicular variant with similar prevalence. No correlation was found between BRAF mutation and aggressive clinical behavior. MASA-PCR proved to be a specific, sensitive and reliable method to detect BRAF T1799A in DNA extracted from different sources, including cytologic samples obtained either fresh or from archival glass slides. We propose this method as a useful tool to improve accuracy of preoperative diagnosis identifying PTC from biopsies with indeterminate cytologic findings.
\end{abstract}

European Journal of Endocrinology 154 341-348

\section{Introduction}

The tyrosine kinase receptor/RAS/RAF/MEK/ERK cascade is a key regulator of cell growth in all eukaryotic cells. Upon activation, ERK phosphorylates cytoplasmic targets (such as RSK and MNK) and translocates to the nucleus, where it stimulates the activity of various transcription factors, leading to activation of the cell cycle (1). In papillary thyroid cancers, aberrant expression of genes coding for the kinase domain of RET or TRK tyrosine kinase receptors, and activating mutations of RAS, are present and all lead to RAF activation. Thus, RAF plays a pivotal role in transformation, as it connects aberrant activating signals to cell-cycle machinery.
The family of $\mathrm{v}$-RAF-related genes comprises three serine/threonine kinase isoforms, A-RAF, B-RAF- and $C-R A F$ - (or $R A F-1$ ), that display both overlapping and unique functions $(2-7)$.

The thymine-to-adenine transversion at nucleotide position 1799 of $B R A F$, which results in a valineto-glutamate substitution at residue 600 (BRAF $^{\mathrm{V} 600 \mathrm{E}}$ formerly position 1796 and residue V599E), occurs in a broad range of human cancers $(8-14)$. This somatic point mutation in the $B R A F$ gene has been identified as the most common genetic event in papillary thyroid carcinoma (PTC) (15-24).

Although this mutation has consistently been reported to be specific for PTC, no benign thyroid 
neoplasms or follicular carcinomas have been found to harbor BRAF mutation, and its prevalence in PTC is quite variable (29-69\%) (Table 1).

Because it offers good sensitivity and specificity as molecular marker of PTC, detection of BRAF mutation on FNAB specimens has been proposed as a diagnostic adjunctive tool in evaluation of thyroid nodules with indeterminate cytologic findings $(25-27)$.

Uncertain prevalence might bias the potential usefulness of the detection of BRAF mutation on FNAB specimens. The sensitivity of detection of BRAF T1799A transversion mutation as diagnostic marker for PTC on FNAB specimens depends on its prevalence and on the technique employed. Genomic amplification by PCR, followed by single-strand conformation polymorphism (SSCP) and validation of the results by DNA sequencing, is the method usually employed to detect BRAF T1799A transversion mutation. Alternative methods proposed are real-time allele-specific amplification, colorimetric mutation detection, and restriction fragment length polymorphism (RFLP) $(26,28,29)$. With the exception of real-time allele-specific amplification, these assays are time-consuming and not always sensitive enough to detect the low percentage of cells containing the mutation. This second limitation might be of great relevance when investigating heterogeneous tissue specimens. Therefore, we developed an assay based on mutant allele-specific amplification (MASA) to detect BRAF T1799A transversion mutation in DNA extracted from fine-needle aspiration biopsy (FNAB) or from archived paraffin-embedded thyroid tissue. Our results, comparing SSCP, direct DNA sequencing and MASA, demonstrate that MASA is a specific and reliable approach to improve the detection of $B R A F$ mutation.

\section{Materials and methods}

\section{Tumor samples and cell lines}

Paraffin-embedded blocks were retrieved from the files of the relevant department (Scienze Biomorfologiche e Funzionali) at the University of Naples, Italy. All tissues had been routinely fixed overnight in buffered formalin. We analyzed 43 papillary carcinomas, 27 follicular carcinomas and three follicular adenomas for $B R A F$ mutation; in addition, five specimens with unremarkable morphology obtained from the lobe contralateral to the tumor in total thyroidectomy samples were also processed. Standard criteria were employed to classify tumors and their variants (30). Twelve were assigned to the follicular variant and separated from PTCs showing classic features $(n=31)$; special care was also taken to select from the files only cases of follicular cancer with unquestionable evidence of vascular invasion $(n=27)$, and to exclude follicular or papillary tumors with oxyphilic changes. All benign and malignant neoplasmic samples were carefully microdissected under a microscope to exclude surrounding normal tissue. BRAF mutation was also assessed both on touch cytologic samples directly obtained from specimens immediately after surgery, and on May-Grunwald Giemsa- or Papanicolau-stained, routine FNAB.

Thyroid carcinoma cell lines NPA (homozygous $B R A F$ mutation at the nucleotide 1799) and WRO (homozygous wild-type $B R A F$ ) were kindly donated by M. Nagao (Tokyo, Japan) (31). All cell lines were cultured in petri dishes in $5 \% \mathrm{CO}_{2}$ atmosphere at $37^{\circ} \mathrm{C}$, in Ham's F-12 medium supplemented with $10 \%$ fetal calf serum (FCS). Study approval was obtained from the institutional review board.

\section{Genomic DNA extraction}

For nucleic acid extraction from paraffin-embedded tissues, $5 \mu \mathrm{m}$ sections were immersed in xylene for 30 min to remove paraffin, and washed in absolute and then in $70 \%$ ethanol. All samples were subjected to digestion with $0.5 \%$ SDS and $0.5 \mathrm{mg} / \mathrm{ml}$ proteinase $\mathrm{K}$ at $37^{\circ} \mathrm{C}$ overnight, extracted with phenol and precipitated with ethanol in the presence of sodium acetate. Genomic DNA extraction from FNAB specimens and from thyroid tumor cell lines was conducted by TRI Reagent (Sigma) $\left(500 \mu \mathrm{l}\right.$ for FNAB and $1 \mathrm{ml} / 10 \mathrm{~cm}^{2}$ of culture plate surface area), according to the manufacturer's instructions. DNA concentration was quantitated by $A^{260}$ absorbance with a BioPhotometer (Eppendorf, Hamburg, Germany). Genomic DNA (50-100 ng/sample) was used as a template.

Table $1 \mathrm{BRAF}^{\mathrm{V} 600 \mathrm{E}}$ prevalence in the literature. Data are expressed as positive/number of cases (percentage).

\begin{tabular}{|c|c|c|c|c|c|}
\hline References & Benign lesions & PTC & PTC classic & PTC follicular variant & FTC \\
\hline$(15)$ & n.d. & 28/78 (35.8) & n.d. & n.d. & $0 / 46(0)$ \\
\hline$(21)$ & $0 / 111(0)$ & $45 / 119$ (37.8) & n.d. & n.d. & $0 / 32(0)$ \\
\hline (19) & $0 / 20(0)$ & $49 / 170(28.8)$ & n.d. & n.d. & $0 / 11(0)$ \\
\hline (18) & $0 / 24(0)$ & $21 / 56(37.5)$ & n.d. & n.d. & $\mathrm{FA} \mathrm{0/18} \mathrm{(0)}$ \\
\hline (33) & n.d. & $41 / 114(35.9)$ & 28/53 (52.8) & $0 / 32(0)$ & n.d. \\
\hline (22) & $0 / 34(0)$ & $8 / 18 *(44.4)$ & n.d. & n.d. & $0 / 5(0)$ \\
\hline (23) & $0 / 6(0)$ & $24 / 60(40)$ & $19 / 35(54.2)$ & $4 / 19(21.0)$ & $0 / 5(0)$ \\
\hline Present study by MASA & $0 / 5(0)$ & $19 / 43(44.2)$ & $14 / 31(45.2)$ & $5 / 12(41.7)$ & $0 / 27(0)$ \\
\hline
\end{tabular}

FA, follicular adenoma; PTC, papillary thyroid carcinoma; FTC, follicular thyroid carcinoma.

*Only sporadic PTC. 


\section{PCR amplification of exon 15 segment of the BRAF}

Two primers (forward, 5'-TCATAATGCTTGCTCTGATAGGA-3'; reverse, 5' GGCCAAAATTTAATCAGTGGA$\left.3^{\prime}\right)$, as described previously (8), were used to amplify a 224 bp fragment of the exon 15 of BRAF containing the site in which T1799A mutation occurs. PCR reactions were performed in $25 \mu \mathrm{l}$ of $1.5 \mathrm{mM} \mathrm{MgCl} 2$, with $200 \mu \mathrm{M}$ deoxynucleoside triphosphates, 50-100 ng genomic DNA, $0.5 \mu \mathrm{M}$ of each primer and $2.5 \mathrm{U}$ EuroTaq DNA polymerase (EuroClone, Celbio, Italy). Thirty-five cycles with annealing temperatures optimized at $58{ }^{\circ} \mathrm{C}$ were used to apply the PCR product. Amplification products were separated on $1.2 \%$ agarose gel and visualized by ethidium bromide staining.

\section{MASA}

Two different forward primers with substitution of a single base at the end of the primer (5'-GTGATTTTGGTCTAGCTACAGT-3' and 5'-GTGATTTTGGTCTAGCTACAGA-3') were designed to amplify the wild-type allele or BRAF T1799A transversion mutation respectively. The sequence of the reverse primer was the same as used before.

The PCR reactions were performed separately in a PTC100 Peltier Thermal Cycler (MJ Research Bio-Rad, Milan, Italy), including an initial denaturation of $2 \mathrm{~min}$ at $94^{\circ} \mathrm{C}$ and subsequent denaturation for $30 \mathrm{~s}$ at $94^{\circ} \mathrm{C}$, annealing for $30 \mathrm{~s}$ at $58^{\circ} \mathrm{C}$ and extension for $30 \mathrm{~s}$ at $72^{\circ} \mathrm{C}$. All samples were re-examined for BRAF mutation at least three times.

\section{SSCP}

SSCP is a method of detecting single base mutations by the mobility of the single-strand DNA under PAGE. Single base mutations may disrupt secondary structure of the single-strand DNA and lead to changes in mobility through polyacrylamide gel mash. PCR products of exon 15 of the BRAF gene were diluted 1:1 with denaturing solution $(1 \%(\mathrm{w} / \mathrm{v})$ bromophenol blue and $99 \%$ formamide) at $95^{\circ} \mathrm{C}$ for $5 \mathrm{~min}$ and immediately placed on ice to prevent reannealing of the single-strand products. Electrophoresis was carried out on the GenePhor Electrophoresis Unit with GeneGel Excel 12.5/24 (Amersham) at $15^{\circ} \mathrm{C}, 650 \mathrm{~V}, 30 \mathrm{~mA}$ and $15 \mathrm{~W}$ for $120 \mathrm{~min}$. Gels were stained with PlusOne silver staining kit (Amersham) according to the manufacturer's instructions.

\section{Sequencing}

Genomic PCR products and/or aberrant SSCP bands were sequenced. PCR reactions in $25 \mu \mathrm{l}$ of final volume were performed as described above. A $2 \mu \mathrm{l}$ aliquot was run on an agarose gel to verify the adequacy of the reaction, and the rest was used for direct sequencing. Sequences were performed with the ET-terminators kit (Amersham) and run on the MegaBACE 500 (Amersham) capillary sequencer.

Sequences were compared by the BLAST program: www.ncbi.nlm.nih.gov/BLAST/ (32).

The PTC cell line NPA was used as a positive control for BRAF T1799A mutation, and the follicular thyroid carcinoma cell line WRO was used as a control for wildtype BRAF gene.

\section{Statistical analysis}

Results were analyzed by the chi-square of independence test or the $t$-test with Prism (Version 3.00 for Windows; GraphPad Software, San Diego, CA, USA). The level of significance was set at $P<0.05$.

\section{Results}

\section{Detection of BRAF mutation by SSCP, DNA sequencing and MASA}

To determine whether different methods to detect T1799A transversion mutation at exon 15 of BRAF gene have different sensitivity and to determine which method is the most sensible, we analyzed a mixture of DNA by SSCP, direct DNA sequencing of PCR products and MASA. The DNA was extracted from WRO cells harboring wild-type BRAF gene and from NPA cells homozygous for BRAF mutation. The two DNA extracts were mixed together at variable ratio, and results obtained by the three methods were compared. The analysis by SSCP revealed that the product of PCR containing the transversion was clearly detectable as a faster band only when the DNA from NPA cells was $60 \%$ or more in the DNA mixture (Fig. 1A). At lower concentration, a faint band corresponding to the mutant allele was sometimes visible. The sensitivity of direct sequencing of the PCR products of the DNA mixture was comparable to that of SSCP, as, at concentrations lower than 60\%, BRAF T1799A was not detected (Fig. 1B). MASA proved to be the most sensitive of the three methods. Each of the two forward primers used generated only the corresponding specific PCR product from wild-type BRAF or when thymidine replaced adenosine at nucleotide position 1799 in the $B R A F$ sequence. A clear band corresponding to BRAF T1799A was always evident also at the lower concentration tested (Fig. 1C). MASA analysis was performed also on DNA extracted from five frozen tissues, five fresh cytologic specimens and four cytologic specimens obtained from fixed and stained archival glass slides. In all cases, MASA proved to be a reliable and rapid method to search for BRAF mutation (Fig. 2). Cytologic material was extracted also from glass slides of inadequate FNAB (Fig. 2D). Although the number of 


\section{A}

$\%$ NPA

020406080100

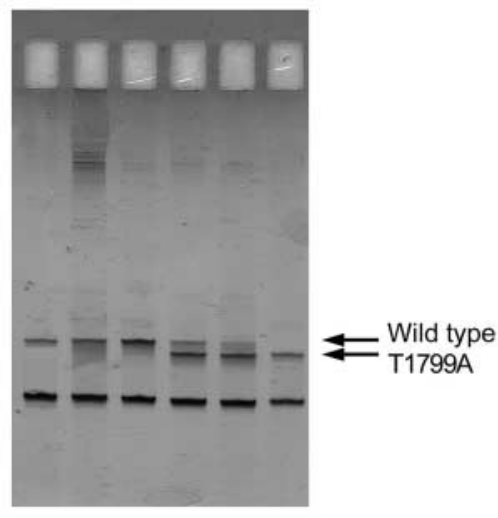

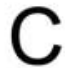

$\%$ NPA

MW $100 \quad 80 \quad 60 \quad 40 \quad 20 \quad 0$

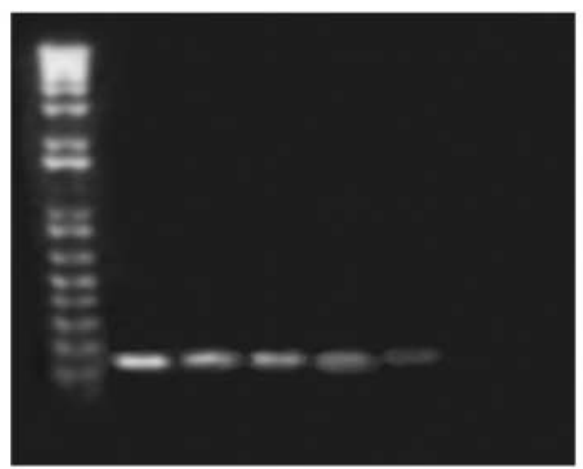

T $A$ C A G

$0 \%$ NPA
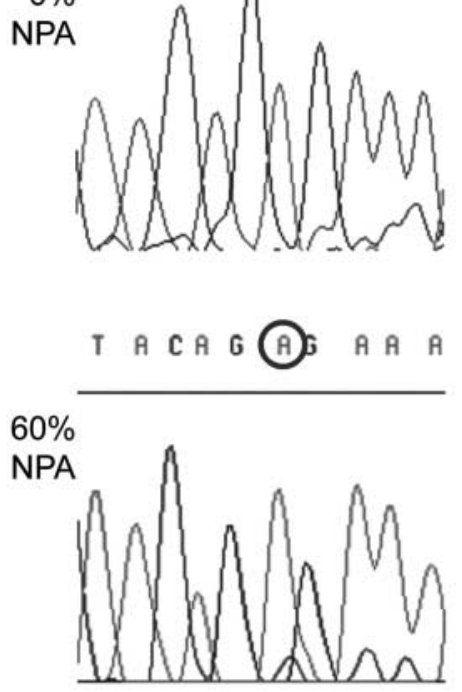

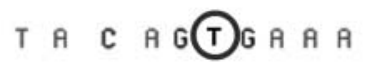

$20 \%$

NPA
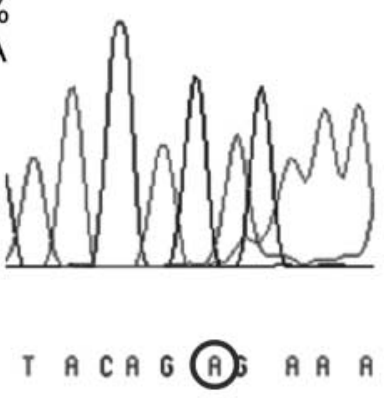

$80 \%$

NPA

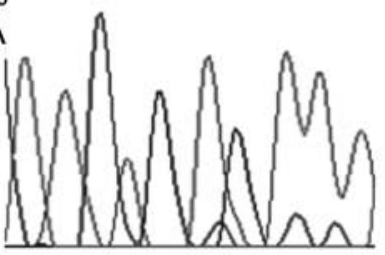

$T$ ค $\subset$ ค $G(\mathrm{~T}$

A $A$

\section{$40 \%$ \\ NPA}
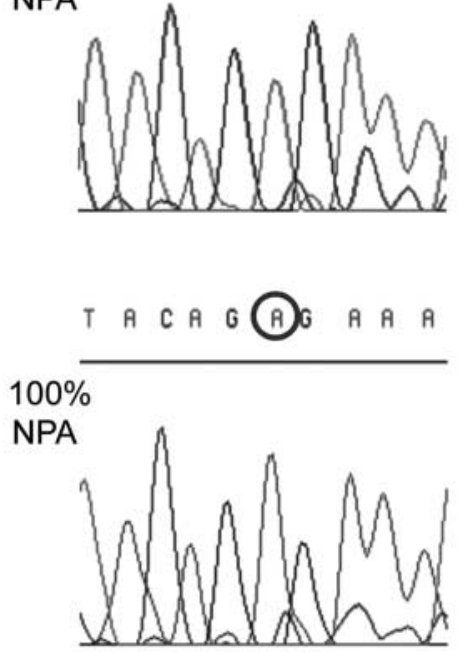

\section{B}

Figure 1 Sensitivity of SSCP, DNA sequencing and MASA. Total DNA extracted from NPA and WRO cells was mixed at variable ratio. The DNA mixtures were analyzed by SSCP (A), direct DNA sequencing of PCR products (B) or MASA (C) to search for T1799A transversion mutation at exon 15 of the BRAF gene. NPA and WRO cells harbor a homozygous BRAF T1799A mutation and wild-type BRAF respectively. Circles indicate nucleotide at 1799 position.

cells was insufficient for the pathologist's morphologic assessment, MASA analysis was feasible. This result suggests that the search for BRAF mutations by MASA may represent a diagnostic adjunctive tool in inadequate FNAB sampling.

\section{Prevalence of BRAF ${ }^{V 600 E}$ in paraffin-embedded thyroid tumors}

By MASA assay, the presence of BRAF mutation was investigated in a series of 78 paraffin-embedded thyroid 


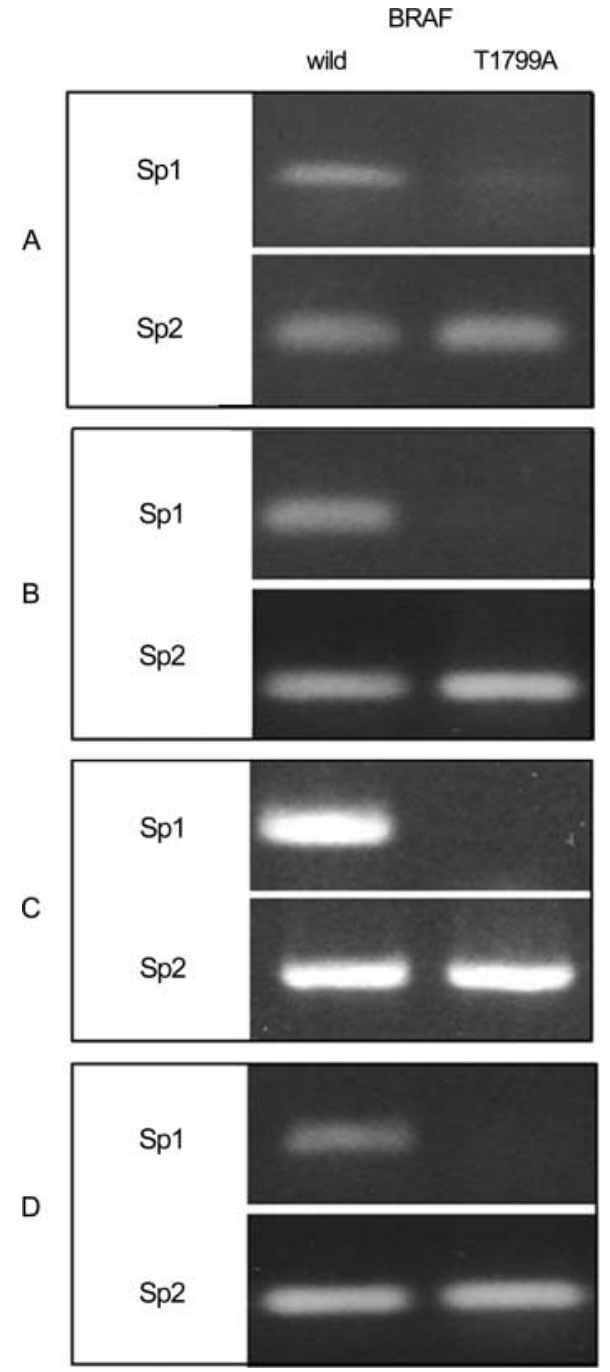

Figure 2 MASA analysis of thyroid specimens. MASA analysis was performed on papillary thyroid cancers from paraffinembedded specimens (A), fresh tissues (B) and fresh cytologic material (C). (D) MASA analysis performed on cytologic material obtained from archival glass slides of inadequate FNAB.

tissues, including five normal thyroids, three follicular adenomas, 27 follicular carcinomas and 43 papillary carcinomas (Table 2). No mutations of BRAF were detected in the normal thyroid tissues, follicular adenomas or follicular carcinomas. In the 43 papillary thyroid cancers studied, 19 displayed BRAF mutation (44.2\%). Further analysis by papillary cancer type showed that $14 / 31$ classic forms $(45.2 \%)$ and $5 / 12(41.7 \%)$ follicular variants were positive for the mutation.

\section{Correlation analysis between BRAF mutation and clinical features}

We examined the correlation between the presence of $B R A F$ mutation and various clinicopathologic features in patients with papillary thyroid cancer. Clinical
Table 2 BRAF prevalence as determined by MASA analysis. Number of cases (percentage).

\begin{tabular}{|c|c|c|c|c|}
\hline & & & \multicolumn{2}{|c|}{$B R A F$ mutation } \\
\hline & & & + & - \\
\hline & & Overall & 19 (44.2) & $24(55.8)$ \\
\hline & PTC 43 & Classic 31 & $14(45.2)$ & 17 (54.8) \\
\hline Thyroid & & Follicular 12 & $5(41.7)$ & 7 (58.3) \\
\hline Tumors & FTC 27 & & 0 & $27(0)$ \\
\hline 78 & FA 3 & & 0 & $3(0)$ \\
\hline & NT 5 & & 0 & $5(0)$ \\
\hline
\end{tabular}

PTC, papillary thyroid carcinoma; FTC, follicular thyroid carcinoma; FA follicular adenoma; NT, normal thyroid.

parameters considered were age at appearance, gender, tumor volume, multicentricity, pTNM classification and stage (Table 3). For 22 patients, recurrence was also considered. The analysis considered overall the papillary thyroid cancer and the classic form or the follicular variant.

No statistically significant correlation was found between BRAF mutation and age at appearance, gender of the patients, multicentricity of the tumor, volume, pTNM classification and stage. However, there was a significant correlation between $\mathrm{BRAF}^{\mathrm{V} 600 \mathrm{E}}$ mutation and absence of node metastasis $(P=0.011$; chi-square of independence test). A postoperative follow-up period of 4-11 years (median 6 years) was considered for 22 patients. All patients were treated with total thyroidectomy, followed by 131-iodine therapy and thyroid-stimulating hormone (TSH)-suppressive therapy with levothyroxine sodium (LT4). Periodically, serum thyroglobulin concentration under LT4 therapy was measured. The follow-up was completed with serum thyroglobulin measurement upon rhTSH subministration and neck ultrasound. Patients were considered free of disease when thyroglobulin was undetectable $(<2 \mathrm{ng} / \mathrm{ml})$ and ultrasound was negative. Withdrawal of LT4 therapy followed by 131-iodine whole-body scan was performed in patients with detectable thyroglobulin and/or positive neck ultrasound. Nine patients of 11 positive for BRAF mutation remained free of disease, and only two recurred. Of the 11 patients negative for BRAF T1799A transversion mutation, seven remained free of disease and four recurred. However, no significant correlation between BRAF mutation and disease outcome was found $(P<0.5$; chi-square of independence test).

\section{Discussion}

To date, oncogenic mutations of BRAF have been confined to exon 15 , resulting in a valine-to-glutamate substitution at residue $600(8,16-18)$. The presence of BRAF mutation has been investigated in several studies with consensus on many findings but also reporting some relevant conflicting results. General agreement has been reached on the restricted 
Table 3 Correlation between BRAF mutation and clinicopathological parameters in 43 cases of papillary thyroid cancer.

\begin{tabular}{|c|c|c|c|}
\hline & BRAF ${ }^{\mathrm{V} 600 E}$ positive & BRAF $^{\mathrm{V} 600 \mathrm{E}}$ negative & $P$ \\
\hline Age median & 40.2 & 43.1 & $0.5^{\star}$ \\
\hline Gender & & & 0.76 \\
\hline male & $2 / 5$ & $3 / 5$ & \\
\hline female & $16 / 32$ & $16 / 32$ & \\
\hline Tumor volume $\mathrm{cm}^{3}$ (mean \pm S.D.) & $15.3 \pm 26$ & $12.9 \pm 14$ & $0.38^{*}$ \\
\hline $\begin{array}{l}\text { Multicentricity } \\
\text { PTNM }\end{array}$ & 4 & 5 & 0.77 \\
\hline T1 & 1 & 2 & 0.59 \\
\hline $\mathrm{T} 2$ & 10 & 3 & 0.05 \\
\hline T3 & 2 & 2 & 0.96 \\
\hline T4 & 5 & 12 & 0.11 \\
\hline No & 18 & 12 & 0.21 \\
\hline N1 & 0 & 7 & 0.01 \\
\hline MO & 18 & 18 & 0.87 \\
\hline \multirow{2}{*}{\multicolumn{4}{|c|}{ Stage }} \\
\hline & & & \\
\hline 1 & 13 & 11 & 0.59 \\
\hline 2 & 4 & 2 & 0.30 \\
\hline 3 & 1 & 5 & 0.12 \\
\hline 4 & 0 & 1 & 0.33 \\
\hline
\end{tabular}

Analysis was by chi-square of independence test or by the $t$-test $\left(^{*}\right)$.

expression of $B R A F$ mutation in papillary tumors and undifferentiated with papillary component tumors in the thyroid gland (21). In view of its selective expression, BRAF ${ }^{\mathrm{V} 600 \mathrm{E}}$ is an ideal hallmark of thyroid cancer with papillary component.

However, although its specificity to differentiate benign nodules from thyroid cancer is $100 \%$, its sensitivity is ambiguous, as its prevalence varies in the different studies from $28.8 \%$ to $44.2 \%$ (Table 1 ). The detection of BRAF mutation in cytologic specimens from thyroid fine-needle aspiration has been proposed to improve the diagnostic accuracy of this procedure, identifying papillary carcinomas with indeterminate cytologic findings. In this regard, sensitivity of $B R A F$ T1799A transversion detection strictly depends upon prevalence of BRAF mutation. From a clinical standpoint, an indeterminate prevalence biases the application of BRAF T1799A detection as a reliable tool to improve preoperative diagnosis. Different prevalences observed in the literature might reflect the heterogeneity of sample groups analyzed or might arise from the application of methods with different sensibility. Others have hypothesized that different prevalence with regard to histologic type of PTC might be responsible for different overall $\mathrm{BRAF}^{\mathrm{V} 600 \mathrm{E}}$ prevalence in the PTC series analyzed. In two different studies, BRAF mutation was not detected in any of the 38 cases of PTC follicular variant analyzed $(24,33)$. In these studies, BRAF mutations were sought by direct DNA sequencing of PCR products, preceded by SSCP analysis in the study by Trovisco et al. (33). Combination of these two methods was used also in the study by Puxeddu et al. (23) but with totally different results, as BRAF mutation was detected in 4/19 specimens of PTC follicular variant. In our study, the prevalence of
BRAF mutation was similar in classic and follicular variants of PTC (45.2\% and $41.7 \%$ respectively; $P=0.99$ ). Hence, while different classic form/follicular variant ratio in the PTC series analyzed might account for only minimal discrepancies in overall PTC prevalence, we have to explain why findings within follicular variant are so conflicting. Searching for BRAF T1799A in serial dilutions of DNA extracted from NPA in DNA from WRO cells revealed that sensibility of SSCP and DNA sequencing is quite low. Both methods could detect this mutation only in samples containing more then $40 \%$ of cells harboring homozygous BRAF mutation. Assuming heterozygosity for the alleles in primitive tumor cells, these methods are unable to detect the mutation in heterogeneous samples. The need for a more sensitive method to lower false-negative results arises also from the possibility that PTC specimens are contaminated by normal surrounding or intranodular cells. Similarly, if BRAF mutation is restricted to the papillary component of thyroid tumors, as suggested by some authors (21), then this mutation can be detected in follicular variant of PTC only when the papillary component is largely prevalent. The possibility that BRAF mutation is not present in all cells within a tumor is worth consideration. Unger et al. (34) searched for RET/PTC rearrangements in papillary thyroid cancers of Ukrainian patients exposed to radiation after the Chernobyl nuclear accident. They demonstrated that only a small proportion of cells harbored the rearrangement, supporting the idea of heterogeneity within the tumor mass. This finding suggests either that these tumors are of polyclonal origin, or that RET rearrangements are a subclonal event (35). As for RET/PTC, theoretically, BRAF mutation could also be present only in a proportion 
of tumor cells. The MASA assay we designed to detect $B R A F$ transversion mutation in thyroid samples proved to be a method more sensitive than SSCP and DNA sequencing of PCR products. This may account for the higher prevalence of $\mathrm{BRAF}^{\mathrm{V} 600 \mathrm{E}}$ we found in overall PTC as well as in the follicular variant. The $B R A F$ prevalence determined in our study is also higher than in $\mathrm{Xu}$ et al.'s study (18), in which MASA-PCR used a primer with substitution of two bases at the $3^{\prime}$-end, designed to amplify only the $B R A F$ mutant allele. Although two nucleotide mismatches may reduce the annealing and amplification of wild-type allele, thus reducing false-positive results, this may yield more false-negative results than using a primer with only one base substitution at the $3^{\prime}$-end, as we did in our study. Primers with one base substitution (T/A) used in our MASA assay warrant a perfect annealing for both wild-type and mutant alleles. The absence of mutations found in 35 benign lesions or follicular carcinomas demonstrates the specificity and reliability of the method employed. Some $10-15 \%$ of FNABs yielded indeterminate diagnosis because of inadequate drawing. The number of cells necessary for nucleic acid analysis is much lower than that necessary for morphologic assessment. Therefore, detection of oncogenes on FNAB specimens has been proposed as a diagnostic adjunctive tool in inadequate FNAB. Our study suggests that the search for BRAF mutations by MASA in cytologic material extracted from glass slides of inadequate FNABs may represent a valid diagnostic adjunctive tool. The method is rapid and easy to perform; however, some limits must be considered. Only a predefined mutation can be detected by MASA whereas new mutations remain hidden. Its effectiveness in the diagnosis of papillary carcinoma is limited by the BRAF prevalence in this type of cancer. In our institution, 24 inadequate FNABs were analyzed by MASA for BRAF mutation. One sample was found to be positive, and the patient underwent thyroidectomy. The diagnosis of PTC of classic form was confirmed by histology. The cancer was not excluded in the BRAF-negative samples because this mutation accounts for only $44.2 \%$ of PTC and even less when all types of thyroid cancer are considered. Therefore, to increase the significance of genetic analysis in indeterminate FNABs, BRAF mutation should be sought together with other oncogenes (RET/PTC, Trk). To date, while a positive MASA assay affects the diagnosis and the consequent therapy, the negative search for $\mathrm{BRAF}^{\mathrm{V} 600 \mathrm{E}}$ does not change a therapeutic decision based on clinical parameters.

Early studies on BRAF expression and clinicopathologic parameters reported a significant association with distant metastasis, extrathyroidal extension and more advanced clinical stage, suggesting that $B R A F$ mutation contributes to the development of an aggressive phenotype $(19,21)$. However, these results have not been confirmed by later studies $(18,23,24)$. Our analysis of clinicopathologic parameters at diagnosis and at 4-11-year follow-up confirmed the lack of association between $\mathrm{BRAF}^{\mathrm{V} 600 \mathrm{E}}$ and aggressive clinical behavior. In our opinion, different sensitivity of methods used to detect BRAF mutation and limitation in size of the studies may account for such discordant findings. Our data suggest the existence of a positive correlation between BRAF mutation and the absence of node metastasis. However, although the association was statistically significant, it must be taken into account that only seven cases presented node metastasis. Such a small number imposes caution in drawing conclusions.

In conclusion, our study demonstrates a higher prevalence of $B R A F$ mutation in PTC and that this mutation is present in the classic form and in the follicular variant with similar frequency. No significant correlation was found between $\mathrm{BRAF}^{\mathrm{V} 600 \mathrm{E}}$ and aggressive clinical behavior. MASA-PCR proved to be a specific, sensitive and reliable method to detect $B R A F$ transversion mutation in small quantities of DNA extracted from different sources, including cytologic material obtained either fresh or from archival glass slides. We propose this method as a useful tool to improve the accuracy of preoperative diagnosis in identifying PTC from biopsies with indeterminate cytologic findings.

\section{Acknowledgements}

This work has been supported in part by Ministero dell'Istruzione, dell'Università e della Ricerca (to M V and G F).

\section{References}

1 Sturgill TW, Ray LB, Erikson E \& Maller JL. Insulin-stimulated MAP-2 kinase phosphorylates and activates ribosomal protein S6 kinase II. Nature $1988334715-718$.

2 Huser M, Luckett J, Chiloeches A, Mercer K, Iwobi M, Giblett S, Sun XM, Brown J, Marais R \& Pritchard C. MEK kinase activity is not necessary for Raf-1 function. EMBO Journal 200120 1940-1951.

3 Mercer K, Chiloeches A, Huser M, Kiernan M, Marais R \& Pritchard C. ERK signalling and oncogene transformation are not impaired in cells lacking A-Raf. Oncogene 200221 347-355.

4 Mikula M, Schreiber M, Husak Z, Kucerova L, Ruth J, Wieser R, Zatloukal K, Beug H, Wagner EF \& Baccarini M. Embryonic lethality and fetal liver apoptosis in mice lacking the c-raf-1 gene. EMBO Journal $2001201952-1962$.

5 Pritchard CA, Bolin L, Slattery R, Murray R \& McMahon M. Postnatal lethality and neurological and gastrointestinal defects in mice with targeted disruption of the A-Raf protein kinase gene. Current Biology 19966 614-617.

6 Wojnowski L, Zimmer AM, Beck TW, Hahn H, Bernal R, Rapp UR \& Zimmer A. Endothelial apoptosis in Braf-deficient mice. Nature Genetics 199716 293-297.

7 Morice C, Nothias F, Konig S, Vernier P, Baccarini M, Vincent JD \& Barnier JV. Raf-1 and B-Raf proteins have similar regional distributions but differential subcellular localization in adult rat brain. European Journal of Neuroscience 199911 1995-2006.

8 Davies H, Bignell GR, Cox C, Stephens P, Edkins S, Clegg S, Teague J, Woffendin H, Garnett MJ, Bottomley W, Davis N, 
Dicks E, Ewing R, Floyd Y, Gray K, Hall S, Hawes R, Hughes J, Kosmidou V, Menzies A, Mould C, Parker A, Stevens C, Watt S, Hooper S, Wilson R, Jayatilake H, Gusterson BA, Cooper C, Shipley J, Hargrave D, Pritchard-Jones K, Maitland N, ChenevixTrench G, Riggins GJ, Bigner DD, Palmieri G, Cossu A, Flanagan A, Nicholson A, Ho JW, Leung SY, Yuen ST, Weber BL, Seigler HF, Darrow TL, Paterson H, Marais R, Marshall CJ, Wooster R, Stratton MR \& Futreal PA. Mutations of the BRAF gene in human cancer. Nature 2002417 949-954.

9 Brose MS, Volpe P, Feldman M, Kumar M, Rishi I, Gerrero R, Einhorn E, Herlyn M, Minna J, Nicholson A, Roth JA, Albelda SM, Davies H, Cox C, Brignell G, Stephens P, Futreal PA, Wooster R, Stratton MR, Weber BL \& BRAF AS. mutations in human lung cancer and melanoma. Cancer Research 200262 6997-7000.

10 Naoki K, Chen TH, Richards WG, Sugarbaker DJ \& Meyerson M. Missense mutations of the BRAF gene in human lung adenocarcinoma. Cancer Research 200262 7001-7003.

11 Singer G, Oldt R 3rd, Cohen Y, Wang BG, Sidransky D, Kurman RJ \& Shih I-M. Mutations in BRAF and KRAS characterize the development of low-grade ovarian serous carcinoma. Journal of the National Cancer Institute 200395 484-486.

12 Chan TL, Zhao W, Leung SY \& Yuen ST. BRAF and KRAS mutations in colorectal hyperplastic polyps and serrated adenomas. Cancer Research 200363 4878-4881.

13 Sommerer F, Vieth M, Markwarth A, Rohrich K, Vomschloss S, May A, Ell C, Stolte M, Hengge UR, Wittekind C \& Tannapfel A. Mutations of BRAF and KRAS2 in the development of Barrett's adenocarcinoma. Oncogene 200423 554-558.

14 Saetta AA, Papanastasiou P, Michalopoulos NV, Gigelou F, Korkolopoulou P, Bei T \& Patsouris E. Mutational analysis of BRAF in gallbladder carcinomas in association with K-ras and p53 mutations and microsatellite instability. Virchows Archiv 2004445 179-182.

15 Kimura ET, Nikiforova MN, Zhu Z, Knauf JA, Nikiforov YE \& Fagin JA. High prevalence of BRAF mutations in thyroid cancer: genetic evidence for constitutive activation of the RET/PTC-RAS-BRAF signaling pathway in papillary thyroid carcinoma. Cancer Research 200363 1454-1457.

16 Cohen Y, Xing M, Mambo E, Guo Z, Wu G, Trink B, Beller U, Westra WH, Ladenson PW \& Sidransky D. BRAF mutation in papillary thyroid carcinoma. Journal of the National Cancer Institute $200395625-627$

17 Soares P, Trovisco V, Rocha AS, Lima J, Castro P, Preto A, Maximo V, Botelho T, Seruca R \& Sobrinho-Simoes M. BRAF mutations and RET/PTC rearrangements are alternative events in the etiopathogenesis of PTC. Oncogene 200322 4578-4580.

$18 \mathrm{Xu}$ X, Quiros RM, Gattuso P, Ain KB \& Prinz RA. High prevalence of BRAF gene mutation in papillary thyroid carcinomas and thyroid tumor cell lines. Cancer Research 200363 4561-4567.

19 Namba H, Nakashima M, Hayashi T, Hayashida N, Maeda S, Rogounovitch TI, Ohtsuru A, Saenko VA, Kanematsu T \& Yamashita S. Clinical implication of hot spot BRAF mutation, V599E, in papillary thyroid cancers. Journal of Clinical Endocrinology and Metabolism $2003 \mathbf{8 8} 4393-4397$.

20 Fukushima T, Suzuki S, Mashiko M, Ohtake T, Endo Y, Takebayashi Y, Sekikawa K, Hagiwara K \& Takenoshita S. BRAF mutations in papillary carcinomas of the thyroid. Oncogene $2003226455-6457$.

21 Nikiforova MN, Kimura ET, Gandhi M, Biddinger PW, Knauf JA, Basolo F, Zhu Z, Giannini R, Salvatore G, Fusco A, Santoro M, Fagin JA \& Nikiforov YE. BRAF mutations in thyroid tumors are restricted to papillary carcinomas and anaplastic or poorly differentiated carcinomas arising from papillary carcinomas. Journal of Clinical Endocrinology and Metabolism 200388 5399-5404.
22 Xing M, Vasko V, Tallini G, Larin A, Wu G, Udelsman R, Ringel MD, Ladenson PW \& Sidransky D. BRAF T1796A transversion mutation in various thyroid neoplasms. Journal of Clinical Endocrinology and Metabolism 200489 1365-1368.

23 Puxeddu E, Moretti S, Elisei R, Romei C, Pascucci R, Martinelli M, Marino C, Avenia N, Rossi ED, Fadda G, Cavaliere A, Ribacchi R, Falorni A, Pontecorvi A, Pacini F, Pinchera A \& Santeusanio F. BRAF(V599E) mutation is the leading genetic event in adult sporadic papillary thyroid carcinomas. Journal of Clinical Endocrinology and Metabolism $2004892414-2420$.

24 Fugazzola L, Mannavola D, Cirello V, Vannucchi G, Muzza M, Vicentini L \& Beck-Peccoz P. BRAF mutations in an Italian cohort of thyroid cancers. Clinical Endocrinology (Oxf) $200461239-243$.

25 Cohen Y, Rosenbaum E, Clark DP, Zeiger MA, Umbricht CB, Tufano RP. Sidransky D \& Westra WH. Mutational analysis of BRAF in fine needle aspiration biopsies of the thyroid: a potential application for the preoperative assessment of thyroid nodules. Clinical Cancer Research $2004102761-2765$.

26 Xing M, Tufano RP, Tufaro AP, Basaria S, Ewertz M, Rosenbaum E, Byrne PJ, Wang J, Sidransky D \& Ladenson PW. Detection of BRAF mutation on fine needle aspiration biopsy specimens: a new diagnostic tool for papillary thyroid cancer. Journal of Clinical Endocrinology and Metabolism $2004892867-2872$.

27 Salvatore G, Giannini R, Faviana P, Caleo A, Migliaccio I, Fagin JA, Nikiforov YE, Troncone G, Palombini L, Basolo F \& Santoro M. Analysis of BRAF point mutation and RET/PTC rearrangement refines the fine-needle aspiration diagnosis of papillary thyroid carcinoma. Journal of Clinical Endocrinology and Metabolism 2004 $895175-5180$.

28 Jarry A, Masson D, Cassagnau E, Parois S, Laboisse C \& Denis MG. Real-time allele-specific amplification for sensitive detection of the BRAF mutation V600E. Molecular and Cellular Probes 200418 349-352.

29 Rimoldi D, Salvi S, Lienard D, Lejeune FJ, Speiser D, Zografos L \& Cerottini JC. Lack of BRAF mutations in uveal melanoma. Cancer Research $2003635712-5715$.

30 Rosai J, Carcangiu ML \& De Lellis RA. Tumors of the thyroid gland. In Atlas of Tumor Pathology, pp 49-62, 3rd series, fascicle 5, Eds J Rosai \& LH Sobin. Washington, DC: Armed Forces Institute of Pathology, 1992.

31 Ishizaka Y, Itoh F, Tahira T, Ikeda I, Ogura T, Sugimura T \& Nagao M. Presence of aberrant transcripts of ret proto-oncogene in a human papillary thyroid carcinoma cell line. Japanese Journal of Cancer Research $1989 \mathbf{8 0} 1149-1152$.

32 Tatusova TA \& Madden TL. BLAST 2 Sequences, a new tool for comparing protein and nucleotide sequences. FEMS Microbiology Letters $1999174247-250$

33 Trovisco V, Vieira de Castro I, Soares P, Maximo V, Silva P, Magalhaes J, Abrosimov A, Guiu XM \& Sobrinho-Simoes M. BRAF mutations are associated with some histological types of papillary thyroid carcinoma. Journal of Pathology $2004 \mathbf{2 0 2}$ 247-251.

34 Unger K, Zitzelsberger H, Salvatore G, Santoro M, Bogdanova T, Braselmann H, Kastner P, Zurnadzhy L, Tronko N, Hutzler P \& Thomas G. Heterogeneity in the distribution of RET/PTC rearrangements within individual post-Chernobyl papillary thyroid carcinomas. Journal of Clinical Endocrinology and Metabolism $2004894272-4279$.

35 Fagin JA. Challenging dogma in thyroid cancer molecular genetics - role of RET/PTC and BRAF in tumor initiation. Journal of Clinical Endocrinology and Metabolism $2004894264-4266$.

Received 4 May 2005

Accepted 17 October 2005 